\title{
Elimination of Aggressive Behavior in Male Mice Lacking Endothelial Nitric Oxide Synthase
}

\author{
Gregory E. Demas, ${ }^{1,6}$ Lance J. Kriegsfeld, ${ }^{1}$ Seth Blackshaw, ${ }^{2}$ Paul Huang, ${ }^{5}$ Stephen C. Gammie, ${ }^{1}$ \\ Randy J. Nelson, ${ }^{1,2}$ and Solomon H. Snyder ${ }^{2,3,4}$ \\ Department of ${ }^{1}$ Psychology, Johns Hopkins University, and Departments of ${ }^{2}$ Neuroscience, ${ }^{3}$ Pharmacology and \\ Molecular Sciences, and ${ }^{4}$ Psychiatry, Johns Hopkins University School of Medicine, Baltimore, Maryland 21218 , \\ 5 Massachusetts General Hospital, Division of Cardiology, Boston, Massachusetts 02114, and Georgia State University, \\ Departments of Psychology and Biology, Atlanta, Georgia 30303
}

\begin{abstract}
Male mice with targeted deletion of the gene encoding the neuronal isoform of nitric oxide synthase $\left(\mathrm{nNOS}^{-/}\right)$display increased aggressive behavior compared with wild-type (WT) mice. Specific pharmacological inhibition of nNOS with 7-nitroindazole also augments aggressive behavior. We report here that male mice with targeted deletion of the gene encoding endothelial NOS (eNOS ${ }^{-1}$ ) display dramatic reductions in aggression. The effects are selective, because an extensive battery of behavioral tests reveals no other deficits. In the residentintruder model of aggression, resident eNOS ${ }^{-1-}$ males show virtually no aggression. Latency for aggression onset is 25-30 times longer in eNOS ${ }^{-1-}$ males compared with WT males in the rare instances of aggressive behaviors. Similarly, a striking lack of aggression is noted in tests of aggression among groups of
\end{abstract}

Nitric oxide (NO) is formed by three distinct enzymes coded by different genes, neuronal NO synthase (nNOS), endothelial NOS (eNOS), and inducible NOS (iNOS) (Jaffrey and Snyder, 1995). Although nNOS is the primary neuronal form of the enzyme, there have been reports of eNOS in neurons (Dinerman et al., 1994; O’Dell et al., 1994; Doyle and Slater, 1997), and genetic manipulations of eNOS may influence hippocampal long-term potentiation (Son et al., 1996). Male mice with targeted deletion of the gene for nNOS $\left(\mathrm{nNOS}^{-/-}\right)$(Nelson et al., 1995) and mice treated with 7-nitroindazole, an in vivo selective inhibitor of nNOS (Demas et al., 1997) display marked increases in aggressive and sexual behavior, The nNOS ${ }^{-1-}$ mice also manifest defects in nocturnal balance coordination (Kriegsfeld et al., 1999). Initial studies of eNOS ${ }^{-1-}$ mice revealed hypertension but grossly normal behavior (Huang et al., 1995; Sheseley et al., 1996).

We now report virtual elimination of aggressive behavior in male $\mathrm{eNOS}^{-1-}$ mice, as well as improved fine motor coordination suggesting reciprocal behavioral roles for eNOS and nNOS. Our in situ hybridization studies reveal eNOS mRNA in blood vessels but not in neuronal populations in the brain.

\footnotetext{
Received March 1, 1999; revised July 15, 1999; accepted July 30, 1999.

This work was supported by US Public Health Service Grants MH-57535 (R.J.N.), MH-57760 (R.J.N.), MH-18501 (S.H.S.), DA-00266 (S.H.S.), and HL-57818 (P.H.) and Research Scientist Award DA-00074 (S.H.S.).

Correspondence should be addressed to Dr. Solomon H. Snyder, Department Neuroscience, Johns Hopkins University School of Medicine, 725 North Wolfe Street, Baltimore, MD 21218.

Copyright (C) 1999 Society for Neuroscience $\quad 0270-6474 / 99 / 190001-\bullet 05.00 / 0$
}

four mice monitored in neutral cages. Although eNOS ${ }^{-/-}$mice are hypertensive ( $14 \mathrm{mmHg}$ blood pressure elevation), hypertension does not appear responsible for the diminished aggression. Reduction of hypertension with hydralazine does not change the prevalence of aggression in eNOS ${ }^{-\prime-}$ mice. Extensive examination of brains from eNOS ${ }^{-1-}$ male mice reveals no obvious neural damage from chronic hypertension. In situ hybridization in WT animals reveals eNOS mRNA in the brain associated exclusively with blood vessels and no neuronal localizations. Accordingly, vascular eNOS in the brain appears capable of influencing behavior with considerable selectivity.

Key words: aggression; hypertension; 7-nitroindazole; nitroarginine; nitric oxide synthase; endothelium

\section{MATERIALS AND METHODS}

Animals and housing conditions. The eNOS ${ }^{-1-}$ mice were derived from animals originally developed by Huang et al. (1995). Controls included littermates of the eNOS ${ }^{-1-}$ mice as well as C57/B16 mice that were bred in the same colony. Behavioral measures for the two groups did not differ so that they were combined for statistical analyses. All animals were 4-6 months of age (sexually mature) at the onset of behavioral testing. Animals were individually housed in polypropylene cages $(27 \times 17 \times 12$ $\mathrm{cm}$ ) in a colony room with a $24 \mathrm{hr}$ light/dark 16/8 photoperiod (lights on at 7 A.M. Eastern Standard Time). Ambient temperature was maintained at $20 \pm 2^{\circ} \mathrm{C}$, and relative humidity was maintained at $50 \pm 5 \%$. Food (Prolab 100; Agway, Syracuse, NY) and tap water were provided $a d$ libitum throughout the experiment.

Resident-intruder aggression. An adult stimulus male mouse (i.e., intruder) was introduced into the home cage of either an experimental or control adult male mouse. Intruder mice were selected randomly from a pool of individually housed breeder males. These males tended not to attack but would respond aggressively if attacked. Intruder mice were marked on the tail with an indelible marker for purposes of identification. The bedding in the home cages was not changed for $10 \mathrm{~d}$ before behavioral testing. The latency to first aggressive encounter, the duration of each aggressive encounter, and the total number of aggressive encoun-

This article is published in The Journal of Neuroscience, Rapid Communications Section, which publishes brief, peerreviewed papers online, not in print. Rapid Communications are posted online approximately one month earlier than they would appear if printed. They are listed in the Table of Contents of the next open issue of JNeurosci. Cite this article as: JNeurosci, 1999, 19:RC30 (1-5). The publication date is the date of posting online at www.jneurosci.org.

http://www.jneurosci.org/cgi/content/full/3509 
ters initiated by the resident male were recorded. Aggression tests lasted $5 \mathrm{~min}$ and were conducted each day for 3 consecutive days between 3 and 5 P.M. A novel pairing of animals was made for each consecutive test, and intruder males were not used more than once per day.

Grouped aggression in neutral arena. Four adult wild-type (WT) or eNOS ${ }^{-1-}$ mice were simultaneously introduced into a clear glass aquarium $(38.5 \times 26.5 \times 30.7 \mathrm{~cm})$. The floors of the aquarium were covered with $2-3 \mathrm{~cm}$ of fresh pine shavings. The latency to first aggressive encounter, the duration of each aggressive encounter, and the total number of aggressive encounters initiated by each male were recorded. Aggression tests lasted 15 min and were conducted in $1 \mathrm{~d}$ between 3 and 5 P.M.

Sensorimotor tests. A battery of sensorimotor tests was used to assess sensory function and motor coordination and balance (Nelson et al., 1995; Crawley and Paylor, 1997). A series of standardized tests to assess anxiety, including tests using an open field and elevated plus maze, was also conducted. Briefly, to assess open field activity, a mouse was placed in an open arena (1 $\mathrm{m}^{2}$ ). An observer recorded the movement of the mouse during the testing period. The floor was marked off by 16 squares, and the number of squares crossed was counted. Also, the amount of time spent in the open field (inner squares) was compared with the time the mouse moved along the walls of the arena. This test was conducted for $10 \mathrm{~min}$. Incidents of grooming and rearing and number of fecal boli produced were recorded. Mice were also placed in the center of an elevated plus maze with two open arms and two closed arms $(67 \times 5.5 \mathrm{~cm})$. The closed arms contained a 15-cm-high, black-tinted Plexiglas panel and a 65-cm-long detachable roof. The maze was mounted $75 \mathrm{~cm}$ above the floor on a tripod. Choice behavior was observed for $5 \mathrm{~min}$, and the number of visits to each arm and the time spent in each arm as well as in the central area were recorded. Incidents of grooming and rearing and number of fecal boli produced were also recorded.

In situ hybridization. In situ hybridization was conducted as previously described (Blackshaw and Snyder, 1997). The cRNA probe used corresponded to the region covering 2583-3499 bp of murine eNOS (Gnanapandithen et al., 1996). This technique uses a digoxigenin label so that resolution is comparable with immunohistochemistry and substantially better than with a radiolabeled probe. Control hybridization with sense probes provided negligible signals. Regions selected for analysis were those in which neuronal localizations of eNOS had been previously reported (Dinerman et al., 1994; O'Dell et al., 1994; Doyle and Slater, 1997). Sections (20-30) were selected at random for examination with the experimenter blinded to the identity of the mice, WT or eNOS ${ }^{-1-}$.

\section{RESULTS}

In routine handling of eNOS ${ }^{-/-}$mice we note marked docility. Thus, in contrast to WT mice, the $\mathrm{NOS}^{-/-}$animals never bite their handlers and are much gentler in disposition. This contrasts markedly with nNOS ${ }^{-/-}$animals, which are extremely aggressive and routinely attack handlers and each other. In groups of animals, agonistic behavior is extremely rare among eNOS ${ }^{-1-}$ male mice.

To examine this behavior in greater detail, we investigated intermale aggression using a resident-intruder model, an experimental model of territorial aggressive behavior (Thurmond, 1975). We focused our studies on males, because female mice typically do not display aggressive behavior in this context. We scored a variety of aggressive behaviors including wrestling, biting, and tail rattling (Fig. 1). The number $\left(t_{(22)}=4.57 ; p<0.01\right)$
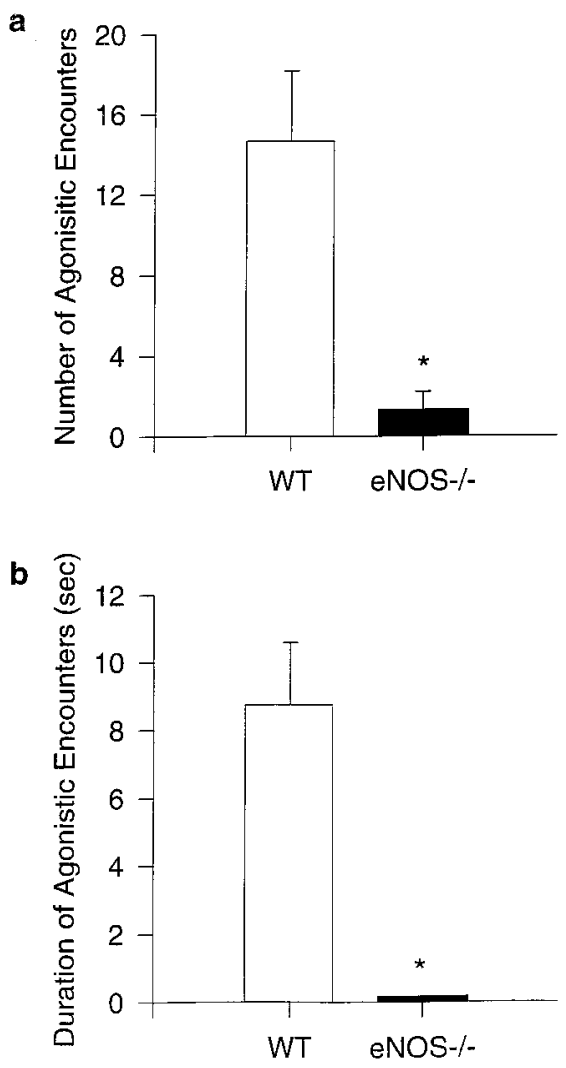

Figure 1. Aggressive behavior in WT $(n=12)$ or $\operatorname{eNOS}^{-/-}(n=12)$ mice in a resident-intruder model. $a$, Mean \pm SEM number of aggressive encounters; $b$, mean \pm SEM duration of aggressive encounters. Data were analyzed by $t$ test. ${ }^{*}$ Statistically significant difference at $p<0.001$.

of aggressive encounters and their duration $\left(t_{(22)}=4.66 ; p<0.01\right)$ are profoundly reduced in the eNOS ${ }^{-1-}$ animals, whose values are not significantly different from zero. The latency to initiate an aggressive encounter is markedly increased for the very few aggressive encounters displayed by eNOS $^{-1-}$ animals $(p<0.001)$.

To evaluate nonterritorial aggression, we observed groups of $\mathrm{WT}_{\text {or eNOS }}{ }^{-1-}$ males together in a large cage (Fig. 2). In this group test, as in the resident-intruder aggressive model, aggressive behavior is virtually eliminated in the $\mathrm{eNOS}^{-1-}$ animals when monitored in terms of the number $\left(t_{(10)}=-5.093 ; p<\right.$ $0.001)$ of aggressive encounters and their duration $\left(t_{(10)}=0.558\right.$; $p>0.05)$. The latency $\left(t_{(10)}=5.21 ; p<0.001\right)$ for the limited number $(3.00 \pm 1.3)$ of attacks by the eNOS ${ }^{-1-}$ mice is $25-30$ times greater than for WT $(60.5 \pm 11)$ animals.

The eNOS $^{-1-}$ mice are derived from two parent strains, C57 and SV 129 (Huang et al., 1995). The depicted experiments (Figs. $1,2)$ compared the mutant mice with WT C57 animals. In other experiments in the same paradigms we detect no difference in aggressive behavior between WT C57 and SV 129 mice or C57-SV 129 hybrid strains (data not shown), confirming our earlier observations (Nelson et al., 1995). Thus, the dramatic reduction of aggression in $\mathrm{eNOS}^{-1-}$ mice does not merely reflect strain variations.

Because the blood pressure of $\mathrm{eNOS}^{-1-}$ animals is $\sim 14 \mathrm{mmHg}$ higher than that of WT controls (Huang et al., 1995; Sheseley et al., 1996), we speculated that the decreased aggressive behavior might reflect hypertension. This seems unlikely, because in models of hypertension that are genetically determined (Potegal and Myers, 1989) or elicited by long-term treatment with sodium 
a

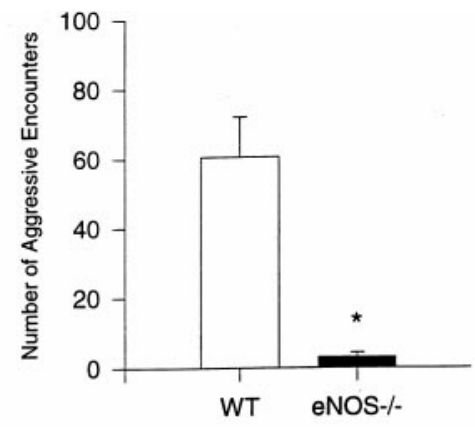

b



c

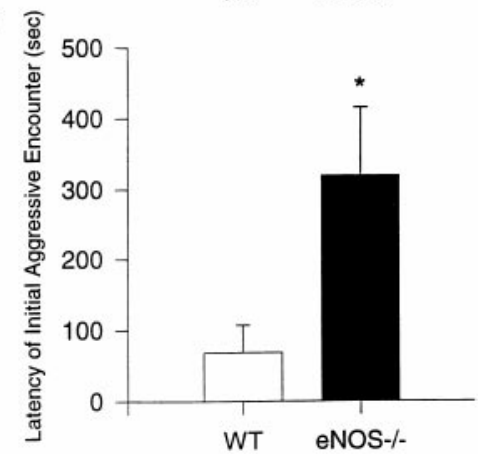

Figure 2. Aggressive behavior in WT or eNOS ${ }^{-1-}$ mice in a grouped aggression model. Six groups of WT and six groups of $\mathrm{eNOS}^{-1-}$ mice were evaluated, with four mice in each group. $a$, Mean \pm SEM number of aggressive encounters; $b$, mean \pm SEM duration of aggressive encounters; $c$, mean \pm SEM latency to initial attack. Symbols, conventions, and statistical analysis are as in Figure 1.

chloride and corticosterone (Simon and Gandelman, 1978), aggressive behavior is generally increased; furthermore, there are no reports of decreased aggression associated with any form of hypertension in animals. To assess whether the eNOS ${ }^{-1-}$ animals display hypertensive encephalopathy, we examined sealed sections of all regions of the brains of the mutant mice with Nissl and DAPI stains and found no morphological differences compared with WT mice (data not shown), similar to previous findings (Kantor et al., 1996; Son et al., 1996).

Although there is no practical way of reversing whatever effects are elicited by lifelong hypertension, we did make an effort to ascertain whether reducing blood pressure of the eNOS ${ }^{-1-}$ animals would affect behavior. We treated the eNOS ${ }^{-1-}$ animals with a regimen of hydralazine administration shown previously to render eNOS ${ }^{-1-}$ animals normotensive (Huang et al., 1995). For $10 \mathrm{deNOS}^{-1-}$ and WT mice received hydralazine in the drinking water $(250 \mathrm{mg} / \mathrm{l}$, resulting in $\sim 1 \mathrm{mg} / \mathrm{d}$ ). We examined aggressive behavior in the resident-intruder neutral arena and group aggression models. No change in aggressive behavior is evident in the behavioral tests (Fig. 3). eNOS ${ }^{-1-}$ mice continue to show dra-

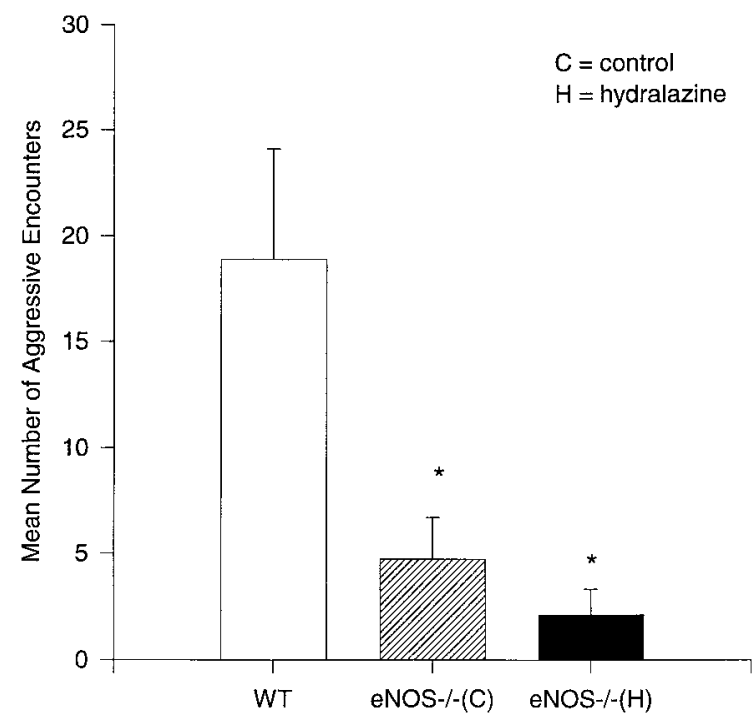

Figure 3. Hydralazine treatment does not alter aggressive behavior of eNOS $^{-1-}$ mice. Mice received hydralazine in their drinking water $(1 \mathrm{mg} / \mathrm{d})$ for $10 \mathrm{~d}$. On the 10th day aggressive behavior was monitored in residentintruder area and group aggression models. Numbers of animals in groups were as indicated in Figures 1 and 2. Hydralazine does not alter aggressive behavior of WT or eNOS ${ }^{-1-}$ mice as analyzed by omnibus $F$ test.

matically reduced aggressive behavior relative to WT mice, and $\mathrm{eNOS}^{-1-}$ mice rendered normotensive with hydralazine do not differ from eNOS ${ }^{-1-}$ controls.

In addition to abnormalities in sexual and aggressive behavior in male $\mathrm{nNOS}^{-1-}$ mice, apparent forelimb strength is decreased, as assessed by the latency to fall from a suspended wire (Nelson et al., 1995). By contrast, we observe a modest increase in forelimb strength in eNOS ${ }^{-1-}$ animals (Table 1). Coordinated performance of eNOS ${ }^{-1-}$ animals is also enhanced in terms of the ability to turn in a blind alley. Apparent alterations in fine motor coordination, such as the ability to turn in a blind alley, could conceivably reflect "emotional" disturbances such as anxiety. However, in anxiety models, such as the elevated plus maze, eNOS $^{-1-}$ animals do not differ from WT mice (Table 1). The

Table 1. Performance of eNOS ${ }^{-/-}$and WT mice in sensorimotor tasks designed to test motor ability, agility, balance-coordination, sensory ability, and strength

\begin{tabular}{|c|c|c|c|c|}
\hline \multirow{2}{*}{$\frac{\text { Task }}{\text { Olfactory ability }}$} & \multicolumn{2}{|c|}{ WT (sec) } & \multicolumn{2}{|c|}{$\mathrm{eNOS}^{-1-}(\mathrm{sec})$} \\
\hline & 359 & \pm 65 & 379 & \pm 66 \\
\hline Turning in an alley & 23.5 & \pm 2.9 & 12.9 & $\pm 2.5^{*}$ \\
\hline Turning on an inclined screen & 8.58 & \pm 2.1 & 6.83 & \pm 1.1 \\
\hline Initiation to walk & 27.5 & \pm 7.3 & 18.6 & \pm 5.1 \\
\hline Balance on a $1 \mathrm{~cm}$ pole & 46.5 & \pm 13 & 36.0 & \pm 10 \\
\hline Balance on a $2 \mathrm{~cm}$ plank & 115 & \pm 3.5 & 104 & \pm 10 \\
\hline Forelimb strength & 22.9 & \pm 5.4 & 70.8 & $\pm 14^{* *}$ \\
\hline \multicolumn{5}{|l|}{ Elevated plus maximum } \\
\hline \multicolumn{5}{|l|}{ Duration (sec) } \\
\hline Closed arms & 156 & \pm 19 & 128 & \pm 30 \\
\hline Central arena128 \pm 22 & 159 & \pm 30 & & \\
\hline \multicolumn{5}{|l|}{ Visits (no.) } \\
\hline Closed arms & 4.2 & \pm 0.8 & 4.4 & \pm 0.9 \\
\hline Central arena & 5.7 & \pm 1.4 & 5.9 & \pm 1.5 \\
\hline
\end{tabular}

Data are mean values \pm SEM for groups of 12 mice.

*,** eNOS ${ }^{-1-}$ differs from Wt; ${ }^{*} p<0.02 ; * * p<0.001$. 


\section{eNOS expression in wildtype and eNOS knockout mice}

\section{Hypothalamus}
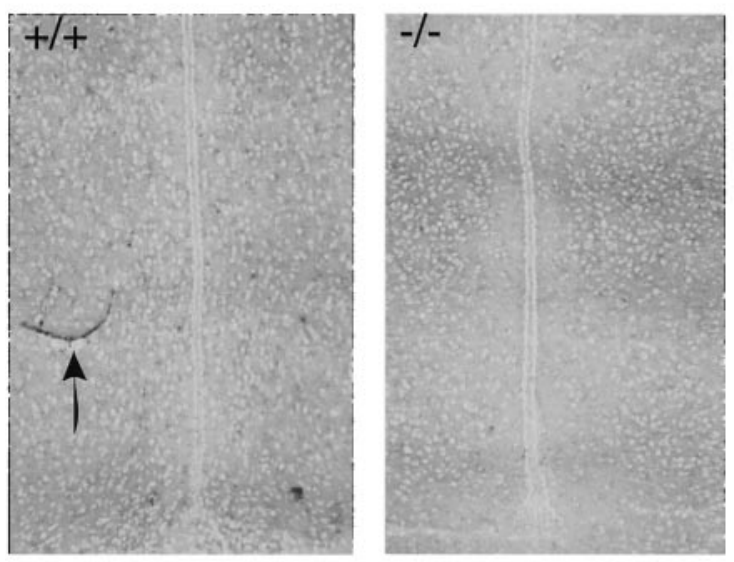

\section{Septum}
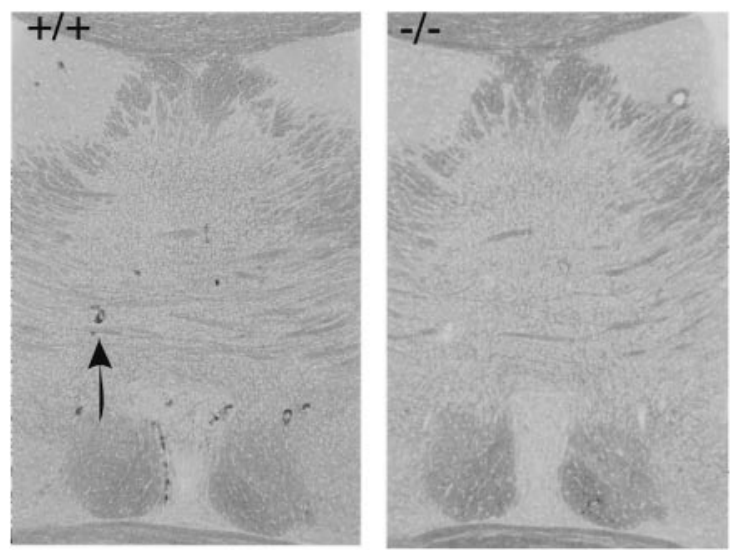

\section{Amygdala}
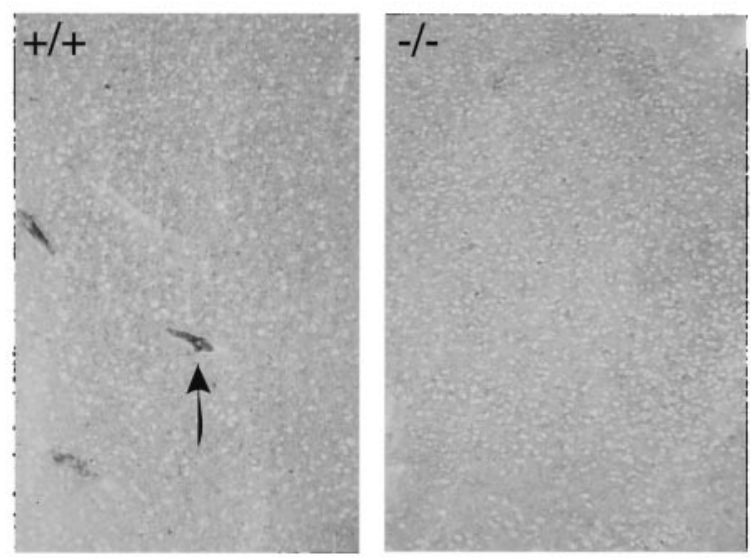

\section{Cerebellum}
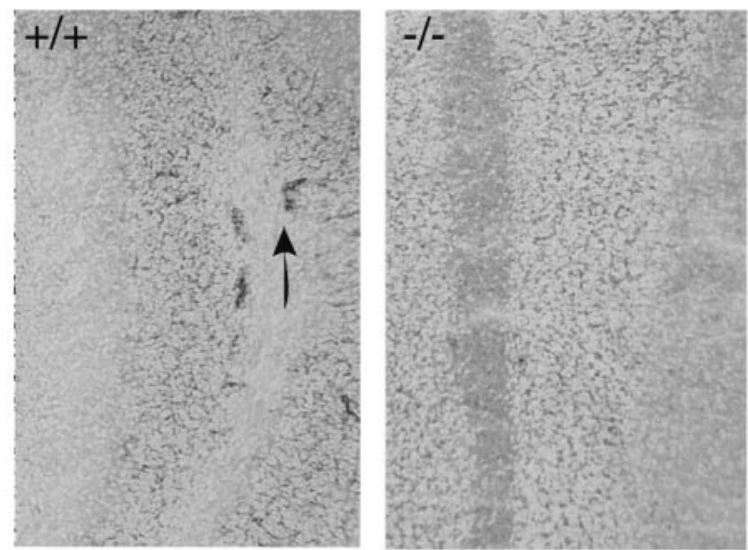

Figure 4. In situ hybridization of endothelial nitric oxide synthase in selected brain regions of WT and eNOS ${ }^{-/-}$mice. Magnification, $100 \times$, except for the septum, which is $50 \times$. Arrows indicate selected eNOS-positive blood vessels. A slight background signal, which does not represent specific hybridization, is seen in white matter of the cerebellum and septum.

alterations in aggressive behavior, forelimb strength, and motor coordination do not seem to derive from generalized behavioral alterations, because most behaviors examined do not differentiate eNOS $^{-/-}$mice from WT animals. Thus, we find no differences in the ability to initiate walking, olfactory ability, visual acuity, tactile behavior, balance, or body mass.

The pronounced alterations of aggressive behavior, as well as apparent forelimb strength and fine motor coordination, in $\mathrm{eNOS}^{-/-}$animals might be associated with alterations in putative neuronal populations using eNOS. eNOS is primarily localized to the endothelium of blood vessels throughout the body, including the brain. However, we (Dinerman et al., 1994; O'Dell et al., 1994) and others (Doyle and Slater, 1997) have reported putative eNOS by immunohistochemistry and NADPH diaphorase staining in some neuronal populations, whereas others have identified eNOS only in blood vessels in the brain (Seidel et al., 1997; Stanarius et al., 1997; Topel et al., 1998). Limitations of such immunohistochemical studies primarily involve the possibility of cross-reactivity of eNOS antibodies with other forms of NOS or with unrelated antigens. NADPH diaphorase staining reflects oxidative enzyme activity using NADPH as an electron donor and so can involve enzymes other than NOS. In situ hybridization using appropriate probes can be much more selective. Because aggressive behavior is presumably mediated primarily through portions of the limbic system, we performed in situ hybridization focusing on the amygdala, the hypothalamus, and the septum, as well as the cerebellum (Fig. 4). The probe we used is a cRNA probe, which, under the high stringency conditions used, is highly specific for eNOS (see Materials and Methods). In all areas of the brain examined, we detect eNOS signal associated with blood vessels but fail to observe any signal in neurons.

\section{DISCUSSION}

The most dramatic finding of this study is the virtual elimination of aggressive behavior in $\mathrm{eNOS}^{-1-}$ animals. Additionally, the $\mathrm{eNOS}^{-1-}$ mice display enhanced forelimb strength and apparent 
fine motor coordination. It is noteworthy that these results are opposite to those observed in $\mathrm{nNOS}^{-/-}$animals that display extraordinary augmentation of aggressive behavior and defects in nocturnal balance coordination and forelimb strength (Nelson et al., 1995; Kriegsfeld et al., 1999).

The behavioral alterations we observe do not appear to reflect any type of nonspecific, general behavioral disruption. We evaluated an extensive sensorimotor repertoire and find no notable abnormalities in eNOS $^{-1-}$ animals. By direct observation, the gross appearance and overall behavior of the $\mathrm{eNOS}^{-/-}$animals do not differ from those of WT mice (Huang et al., 1995; Sheseley et al., 1996). The absence of any gross behavioral abnormalities is consistent with our failure to observe any neuroanatomical defect despite careful examination of multiple sections from many brain regions, similar to findings of others (Huang et al., 1995; Sheseley et al., 1996).

To ascertain the cellular substrate for any behavior associated with eNOS, we conducted in situ hybridization with a highly specific probe and observe label in blood vessels but not in neurons. In earlier studies using an antibody directed against eNOS peptide, we observed neuronal localizations (Dinerman et al., 1994; O'Dell, 1994). As controls, the earlier studies observed elimination of staining with preabsorption using the peptide and the absence of staining with preimmune serum. However, these types of controls do not rule out cross-reactivity with other proteins. Recent immunohistochemical studies using a number of selective eNOS antibodies reveal staining confined to blood vessels (Seidel et al., 1997; Stanarius et al., 1997; Topel et al., 1998). In our own recent studies we also observed immunoreactivity for eNOS restricted to blood vessels in the brain (S. Blackshaw, M. Eliasson, and S. H. Snyder, unpublished observations).

How might eNOS in blood vessels exert such selective influences on behavior? eNOS does not occur uniformly in all vessels. It tends to be most enriched in large and medium-size blood vessels, although there is some eNOS in small arterioles and veins, which lack smooth muscle (Catalan et al., 1996; Seidel et al., 1997; Stanarius et al., 1997; Topel et al., 1998). The selective regulation of behavior by $\mathrm{NO}$ derived from blood vessels is highlighted by the absence of observable morphological alterations in the brain, as well as the selectivity of the behavioral changes. Furthermore, the observation that behavior is improved in measures such as general motor coordination and forelimb strength argues against hypertensive encephalopathy as an explanation of the altered behaviors.

The apparent reciprocal regulation of behavior by nNOS and eNOS in the brain is puzzling, especially because one of the enzymes is neuronal and the other is associated with blood vessels. However, the fact that cerebral blood vessels of all sizes show extensive innervation (Kobayashi et al., 1985; MacKenzie and Scatton, 1987; Iadecola et al., 1993; Ruat et al., 1995) raises the possibility that NO derived from eNOS located in endothelial cells of the brain may diffuse to nearby neurons and influence their activity. This notion is supported by data demonstrating the importance of NO derived from eNOS in the control of inhibitory neurotransmitter release in mouse cerebral cortex (Kano et al., 1998).

\section{REFERENCES}

Blackshaw S, Snyder SH (1997) Parapinopsin, a novel catfish opsin localized to the parapineal organ, defines a new gene family. J Neurosci 17:8083-8092.

Catalan RE, Martinez AM, Argones MD, Hernandez F (1996) Identification of nitric oxide synthases in isolated bovine brain vessels. Neurosci Res 25:195-199.
Crawley JN, Paylor R (1997) Proposed test battery and constellations of specific behavioral paradigms to investigate the behavior phenotypes of transgenic and knockout mice. Horm Behav 31:197-211.

Demas GE, Eliasson MJL, Dawson TM, Dawson VL, Kriegsfeld LJ, Nelson RJ, Snyder SH (1997) Inhibition of neuronal nitric oxide synthase increases aggressive behavior in mice. Mol Med 3:610-616.

Dinerman JL, Dawson TM, Schell MJ, Snowman A, Snyder SH (1994) Endothelial nitric oxide synthase localized to hippocampal pyramidal cells: implications for synaptic plasticity. Proc Natl Acad Sci USA 91:4214-4218.

Doyle CA, Slater P (1997) Localization of neuronal and endothelial nitric oxide synthase isoforms in human hippocampus. Neuroscience 76:387-395.

Gnanapandithen K, Chen Z, Kau CL, Gorczynski RM, Marsden PA (1996) Cloning and characterization of murine endothelial constitutive nitric oxide synthase. Biochim Biophys Acta 1308:103-106.

Huang PL, Huang Z, Mashimo H, Bloch KD, Moskowitz MA, Bevan JA, Fishman MC (1995) Hypertension in mice lacking the gene for endothelial nitric oxide synthase. Nature 377:329-242.

Iadecola C, Beitz AJ, Renno W, Xu X, Mayer B, Zhang F (1993) Nitric oxide synthase containing neural processes on large cerebral arteries and cerebral microvessels. Brain Res 19:148-155.

Jaffrey S, Snyder SH (1995) Nitric oxide: a neural messenger. Ann Cell Dev Biol 11:417-440.

Kano T, Shimizu-Sasamata M, Huang PL, Moskowitz MA, Lo EH (1998) Effects of nitric oxide synthase gene knockout on neurotransmitter release in vivo. Neuroscience 86:695-699.

Kantor DB, Lanzrein M, Stary SJ, Sandoval GM, Smith WB, Sullivan BM, Davidson N, Schuman EM (1996) A role for endothelial NO synthase in LTP revealed by adenovirus-mediated inhibition and rescue. Science 274:1744-1748.

Kobayashi H, Magnoni MS, Govoni S, Izumi F, Wada A, Trabucchi M (1985) Neuronal control of brain microvessel function. Experientia 41:427-434.

Kriegsfeld LJ, Eliasson MJL, Demas GE, Blackshaw S, Dawson TM, Nelson RJ, Snyder SH (1999) Nocturnal motor coordination deficits in neuronal nitric oxide synthase knock-out mice. Neuroscience 89:311-315.

MacKenzie ET, Scatton B (1987) Cerebral circulatory and metabolic effects of perivascular neurotransmitters. CRC Crit Rev Clin Neurobiol 2:357-419.

Nelson RJ, Demas GE, Huang PL, Fishman MC, Dawson VL, Dawson TM, Snyder SH (1995) Behavioural abnormalities in male mice lacking neuronal nitric oxide synthase. Nature 378:383-386.

O'Dell TJ, Huang PL, Dawson TM, Dinerman JL, Snyder SH, Kandel ER, Fishman MC (1994) Endothelial NOS and the blockade of LTP by NOS inhibitors in mice lacking neuronal NOS. Science 265:542-546.

Potegal M, Meyers MM (1989) Spontaneously hypertensive Wistarderived male rats are more aggressive than those of their normotensive progenitor strain. Behav Neural Biol 51:247-261.

Ruat M, Molliver ME, Snowman AM, Snyder SH (1995) Calcium sensing receptor: molecular cloning in rat and localization to nerve terminals. Proc Natl Acad Sci USA 92:3161-3165.

Seidel B, Stanarius A, Wolf G (1997) Differential expression of neuronal and endothelial nitric oxide synthase in blood vessels of the rat brain. Neurosci Lett 239:109-112.

Sheseley EG, Maeda N, Kim HS, Desai KM, Krege JH, Laubach VE, Sherman PA, Sessa WC, Smithies O (1996) Elevated blood pressure in mice lacking endothelial nitric oxide synthase. Proc Natl Acad Sci USA 93:13176-13181.

Simon NG, Gandelman R (1978) Influence of corticosterone on the development and display of androgen-dependent aggressive behavior in mice. Physiol Behav 20:391-396.

Son H, Hawkins RD, Martin K, Kiebler M, Huang PL, Fishman MC, Kandel ER (1996) Long-term potentiation is reduced in mice that are doubly mutant in endothelial and neuronal nitric oxide synthase. Cell 87:1015-1023.

Stanarius A, Topel I, Schulz S, Noack H, Wolf G (1997) Immunocytochemistry of endothelial nitric oxide synthase in the rat brain: a light and electron microscopical study using the tyramide signal amplification technique. Acta Histochem 99:411-429.

Thurmond JB (1975) Technique for producing and measuring territorial aggression using laboratory mice. Physiol Behav 14:879-881.

Topel I, Stanarius A, Wolf G (1998) Distribution of the endothelial constitutive nitric oxide synthase in the developing rat brain: an immunohistochemical study. Brain Res 30:788:43-48. 